\title{
KIDNEY EXCHANGE AND THE ETHICS OF GIVING
}

\author{
Philippe van Basshuysen
}

$(1)$

VER 1.2 MILLION PEOPLE worldwide die of kidney disease each year, making it a little-noticed epidemic, comparable in scale to all deaths by road injuries. ${ }^{1}$ Increasing the number of kidney transplants from live or deceased donors would save many lives, and would improve the life expectancy and quality of many more. At present, there is a striking shortage of kidneys for transplantation.

Many patients have willing live donors who cannot donate to their loved ones because they are biologically incompatible. Kidney exchange (KE) promises relief. For example, suppose your partner needs a kidney but you cannot donate because you are incompatible. If the same is true of a different donor-recipient pair, it may be possible for you to donate to the other recipient and your partner to get the other donor's kidney. Moreover, some people decide to donate altruistically, that is, they give a kidney to a stranger without receiving anything in return. Their gifts can trigger chains of KE, thus multiplying the benefits from a single donation. Below, a detailed description of different types of KE will be provided.

However, KE frequently meets ethical objections, in particular concerning the protection of live donors. These objections are embodied in the transplant laws in many countries, which prohibit live organ donations to strangers, making the implementation of a broad range of KE procedures illegal. In light of the shortage of kidneys for transplantation, it is an urgent matter to clarify the ethics underlying KE.

This paper aims to do that. It examines the implications for live kidney donations of some weak tenets from the ethics of giving. What I call the effectiveness principle is such a tenet. It says, roughly, that if a donation can either be allocat-

1 On kidney disease, see Wang et al., “Global, Regional, and National Life Expectancy, AllCause Mortality, and Cause-Specific Mortality for 249 Causes of Death, 1980-2015," 1483, 1490. The study estimates the number of deaths by road injuries worldwide at 1.3 million to 1.4 million annually (1491). 
ed to benefit some persons, or be allocated to benefit more persons than the first allocation, and the benefits to everyone are approximately identical, then we ought to choose the second allocation. This principle implies that, when an autonomous donor is given a choice between donating into a waiting list or into $\mathrm{KE}$, in many cases morality requires the latter. $\mathrm{KE}$ is thus instrumental in meeting a moral obligation, which provides a novel argument for KE.

I also examine possible ethical objections to KE that might block the argument. Throughout, the German transplant law is used as a case study that expresses many of those concerns. I seek to distinguish the objections that are well-founded from those that are not and for the former, discuss their implications for different types of KE. It will be argued that even conservative views on donor protection and distributive justice, while possibly justifying restrictions of some types of KE procedures, do not in principle oppose the implementation of KE programs.

Finally, I consider possible implications of KE for donors' motivations to donate. KE programs use matching algorithms that maximize the number of transplantations; in particular, in their presence, a donation can trigger $>1$ life savings. Therefore, KE may increase the motivation for donating, which constitutes a further advantage of KE. Together, these arguments make a robust case in favor of providing a legal framework that allows implementing KE programs.

This paper is organized as follows. Section 1 argues for some weak principles from the ethics of giving. Section 2 explains the rationale for and basic procedures of KE. Section 3 examines the implications of the introduced principles for the allocation of kidneys, which provides an argument for KE. Section 4 considers some of the critics' concerns and argues that they might restrict some procedures of KE, but they do not in principle reject the permissibility of Ke programs. Section 5 considers motivational aspects of live kidney donations, which constitute a further argument for KE. Section 6 concludes.

\section{THE CONDITIONAL OBLIGATION TO DONATE EFFECTIVELY}

Before turning to the allocation of kidneys, some basic principles from the ethics of giving will be introduced. The philosophy of effective altruism has recently drawn increased attention to this ethical branch. Effective altruists believe that charitable giving should be done in a way that is most efficient in promoting the most good. ${ }^{2}$ Effective altruism raises two questions. First, to what extent (if at all) is there a moral imperative for individuals to give resources to good causes;

2 E.g., Singer, The Most Good You Can Do; MacAskill, Doing Good Better. The former includes a chapter on altruistic kidney donations. 
and second, if someone decides to give some of their resources to a good cause, what does morality imply for their allocation? We will only be concerned with the second, conditional question. To answer it, weak principles suffice that many people who are not effective altruists will find acceptable as well. The following trolley problem, which stems from Theron Pummer, may help to find these principles. $^{3}$

A trolley on a track $A$ is headed for one innocent person, and another trolley on a track $B$ is headed for one hundred different, innocent persons. Each trolley will kill everyone on its track with certainty—unless you stop it. You can stop one but not both trolleys by laying your arm on the respective track. If you do so, you will lose your arm but everyone on that track will be rescued and nothing else will happen to you.

In line with the above, we make no claim as to whether there is a moral obligation to stop a trolley by sacrificing your arm. Instead, we are interested in the conditional question: If you choose to help, which trolley should you stop? Most will agree that you ought to stop trolley $B$. It would not be permissible to stop trolley $A$ because you would only save one life instead of one hundred by bearing the identical cost, namely your arm. Your rescuing would be terribly ineffective. This appears to be a robust moral intuition. For instance, suppose that, instead of sacrificing a limb, you can donate an amount of money to stop one of the trolleys (but not both). Or suppose that your donation (be it money or your arm) will not save the lives of the persons on a track but would merely prevent them from having short, miserable, or diseased lives, where this benefit would roughly be the same for each beneficiary, no matter on which track. The felt conditional obligation to benefit many, rather than few, when the benefit is the same for each person, holds under a broad range of variations of the problem. Accordingly, we shall assume the following principle:

Effectiveness principle: If one and the same donation can either be allocated to benefit some persons, or be allocated to benefit more persons than the first allocation, and the benefit is roughly identical for each person under the two possible allocations, then, other things being equal, there is a conditional moral obligation to choose the second allocation.

It is worth emphasizing that the effectiveness principle, while implied by effective altruism, is weaker and therefore less controversial than effective altruism. ${ }^{4}$ For instance, effective altruism is demanding in terms of the cause that

3 Pummer, "Whether and Where to Give."

4 Two referees of this journal kindly point out that some philosophers might nevertheless dis- 
you should support. If fighting malaria brings about the most good in the most cost-effective way, then effective altruism may imply that you ought not to support charities fighting homelessness in developed countries. The effectiveness principle would only make this recommendation if the benefits were roughly identical for each beneficiary and the beneficiaries under the former intervention more numerous. But typically, these benefits are unequal for the homeless in developed countries and persons suffering from malaria. Furthermore, effective altruism is typically thought to rely on a consequentialist and welfarist moral theory. The effectiveness principle presupposes neither, as the conditional obligation implicated by it could instead be argued to arise, for instance, from fulfilling more claims to our aid.

The effectiveness principle is equipped with an other-things-being-equal clause in order to accommodate factors that can make a difference in various moral theories. For example, suppose the person on $\operatorname{track} A$ is a friend or family member. This and other "agent-relative" reasons break the symmetry between the two tracks, and they may justify bringing about outcomes that are less than

agree that the effectiveness principle applies in general. While the intricate theoretical discussions about the ethics of giving are beyond the scope of this paper, there is a reason why the effectiveness principle is rather innocuous in the context of altruistic kidney donation. To see why, consider a variation of the trolley problem, in which stopping trolley $B$ would rescue all 101 persons. For example, this could be incorporated by assuming that stopping trolley $B$ also induces trolley $A$ to stop, but not vice versa. Various philosophers, e.g., Parfit ("Future Generations") and Horton ("The All or Nothing Problem"), have discussed similar cases. These cases are weaker than the trolley problem I use here because choosing to do good effectively comes with no opportunity cost: by rescuing many on track $B$ you also rescue the one on track $A$, whereas you sacrifice the one by rescuing many in the initial problem.

McMahan ("Doing Good and Doing the Best") argues that a conditional obligation to donate effectively only arises in cases, such as Horton's and Parfit's, in which doing good effectively has no opportunity cost. As we shall see, donating a kidney effectively can sometimes have opportunity costs, that is, someone who would have benefitted from a given less-than-effective donation might not benefit from an effective donation. Thus, prima facie, it seems that if one maintains, in line with McMahan, that a conditional obligation to donate effectively only arises in no-opportunity-cost cases, one should reject that such an obligation arises in cases of kidney donations.

However, there is a reason to believe that such an obligation does arise in the context of kidney donations, even if one maintains that a conditional obligation to donate effectively only arises in no-opportunity-cost cases. The reason is that an altruistic kidney donor does not usually know ex ante whether or not she is in a no-opportunity-cost case because she does not know the identity of the beneficiaries of her possible (effective or less-than-effective) donations. (See section 2 for the details of altruistic kidney donations.) Since she could well be in a no-opportunity-cost case, she might be morally required to donate her kidney effectively. Thus, if she does not donate effectively, she risks violating this moral requirement. Therefore, she ought to donate effectively. 
optimal from an impartial point of view. ${ }^{5}$ There are also other possible circumstances that may block the consequent of the effectiveness principle, for example, if the person on track $A$ would die with certainty whereas the persons on $\operatorname{track} B$ would have a nonzero chance of survival, or if helping has bad side effects. The other-things-being-equal clause is supposed to capture all such relevant considerations.

I shall next extend the effectiveness principle minimally along three independent lines. Each will be motivated by slightly altering the trolley problem.

1. We assumed above that your sacrificing an arm will stop a trolley with certainty. But suppose instead that your arm only slows a trolley down, stopping it later, so there is a small, positive probability that it will still reach any given person on its track. You have no reason to believe that this probability differs systematically for different persons, or different tracks: from your perspective, indistinguishable strangers stand at roughly the same distance on both tracks from indistinguishable trolleys that approach with roughly the same speed. Arguably, under this variation of the problem the effectiveness principle continues to hold. Since you cannot rationally differentiate between the probabilities of different persons being overrun or saved, the only morally relevant feature that distinguishes tracks $A$ and $B$ is the number of persons on them, just as before. So we shall assume that the effectiveness principle holds in cases in which the benefits of the donation accrue to beneficiaries with probabilities smaller than 1 , where the donor has no reason to believe that the probabilities of the benefits accruing to the persons under the first allocation differ systematically from the probabilities of the benefits accruing to the persons under the second allocation.

It is worth noting that this extension of the effectiveness principle is weaker than a principle prescribing the maximization of expected value. The latter would require sacrificing your arm on track $B$ even when the probability of surviving for the persons on $\operatorname{track} B$ were much lower than for the person on track $A$. Our extension is silent about cases in which these probabilities differ.

2. Suppose that your motivation for stopping a trolley is not to rescue lives, but a different goal, such as meeting social expectations, or the desire to be seen as a hero. It seems that if such a non-altruistic motive is the driver behind the decision to help it would nevertheless be morally wrong to rescue only one person instead of many. (Note that, in 
this case, you do not have agent-relative reasons that would break the symmetry of the options.) So the thought experiment advocates the effectiveness principle even when the donor's motivation for donating is not altruistic.

3. Finally, suppose a stranger is in the choice situation and you, instead of stopping the trolley yourself, observe her free choice. If she decides to stop a trolley, no matter on which track, you can prevent her from doing so. Suppose she decides to stop trolley $B$, thus rescuing one hundred persons. Most of us will likely have the intuition that it would be morally wrong of you to stop her from doing so. (Perhaps the case would be more difficult should she decide to stop trolley $A$ instead, but for our purposes this can be ignored.) There are limits to this intuition. For example, suppose the donor would not only lose her arm but would also bleed to death. Many think we should prevent people from sacrificing their lives. We shall assume that, within reasonable limits, one ought not to prevent a donor from exercising her conditional obligation under the effectiveness principle. We need not take a stance here on how to set the reasonable limits in general, although we will touch on it below with respect to kidney donations.

For the rest of this paper, the effectiveness principle and its three extensions will be assumed. We will employ them in section 3 . Before doing so, we introduce $\mathrm{KE}$ in some depth.

\section{KIDNEY EXCHANGE AND ALTRUISTIC DONATIONS}

Worldwide, there is a growing number of patients on waiting lists for kidneys. These are patients who suffer from end-stage renal disease, that is, their existing kidneys have failed. In most countries, there is a sizeable shortage of kidneys for transplantation. For example, in the Us, 83,978 people were on the deceased donor waiting list for kidneys in 2015, 5,400 in the UK, and around 8,000 in Germany. ${ }^{6}$ The average time a person spends on these waiting lists is two-and-a-half

6 For the us data, see https://www.usrds.org/2017/view/v2_06.aspx, accessed April 11, 2018. The number refers to dialysis patients only. For the uk data, see https://www.organdonation. nhs.uk/news-and-campaigns/news/nhs-blood-and-transplant-reveals-nearly-49-0oo -people-in-the-uk-have-had-to-wait-for-a-transplant-in-the-last-decade, accessed April 11, 2018. For the Germany data, see http://statistics.eurotransplant.org/index.php?search type $=\&$ search_organ $=$ kidney\&search_region=all+et\&search_period=by+year\&search_ characteristic=\&search_text, accessed April 11, 2018. 
to three years in the UK, almost four years in the US, and around six years in Germany. ${ }^{7}$

In the meantime, many receive dialysis. But dialysis diminishes patients' quality of life and their life expectancy, and many die while on the waiting list. Moreover, dialysis is extremely expensive, thus putting a strain on healthcare services and requiring a medical infrastructure that is unavailable in many countries, especially developing countries. ${ }^{8}$ Kidney transplants would extend many patients' life expectancy and life quality, and they are in most cases the cheaper alternative to dialysis. Thus, there is an urgent need to increase the supply of kidneys.

Healthy people have two kidneys and can donate one. Live donor kidney transplants offer the best prospects with respect to recipients' life expectancy and quality. ${ }^{9}$ However, because of incompatibility, mostly due to blood types, or specific antibodies of the recipient, many willing donors are not eligible to donate to their loved ones. ${ }^{10}$ KE promises relief for these patients. KE programs use matching algorithms to determine matches between donors and recipients that increase the number and quality of transplants. To ensure an informed discussion of the ethics of $\mathrm{KE}$, I shall in the following introduce the main KE procedures in depth.

The simplest KE procedure is "two-way kidney paired donation," as shown in part A of figure 1. This procedure matches two incompatible donor-recipient pairs that are mutually compatible. So the donor of the first pair must be compatible with the recipient of the second pair, and the donor of the second pair compatible with the recipient of the first pair, in order for the exchange to happen. This requirement of reciprocal compatibility can be relaxed if, additionally, more than two-way paired donations are feasible. ${ }^{11}$ For example, part $\mathrm{B}$ in figure 1 shows a three-way paired donation.

Other forms of KE alleviate the requirement of reciprocal compatibility by combining paired donations with altruistic donations. An altruistic, or "non-di-

7 For the UK data, see https://www.nhs.uk/conditions/kidney-transplant/waiting-list, accessed April 11, 2018. For the Us data, see https://www.usrds.org/2017/view/v2_06.aspx, accessed April 11, 2018. For the Germany data, see https://www.dso.de/organspende -und-transplantation/warteliste-und-vermittlung/niere.html, accessed April 11, 2018.

8 Wang et al., "Global, Regional, and National Life Expectancy, All-Cause Mortality, and Cause-Specific Mortality for 249 Causes of Death, 1980-2015," 1525.

9 E.g., Wallis et al., "Kidney Paired Donation."

10 Referring to data from the Global Observatory on Donation and Transplantation, Biró et al. report that "depending on the country, $40 \%$ or more of recipients are incompatible with their intended donors" ("Building Kidney Exchange Programmes in Europe," 6).

Roth, Sönmez, and Ünver, "Efficient Kidney Exchange.” 

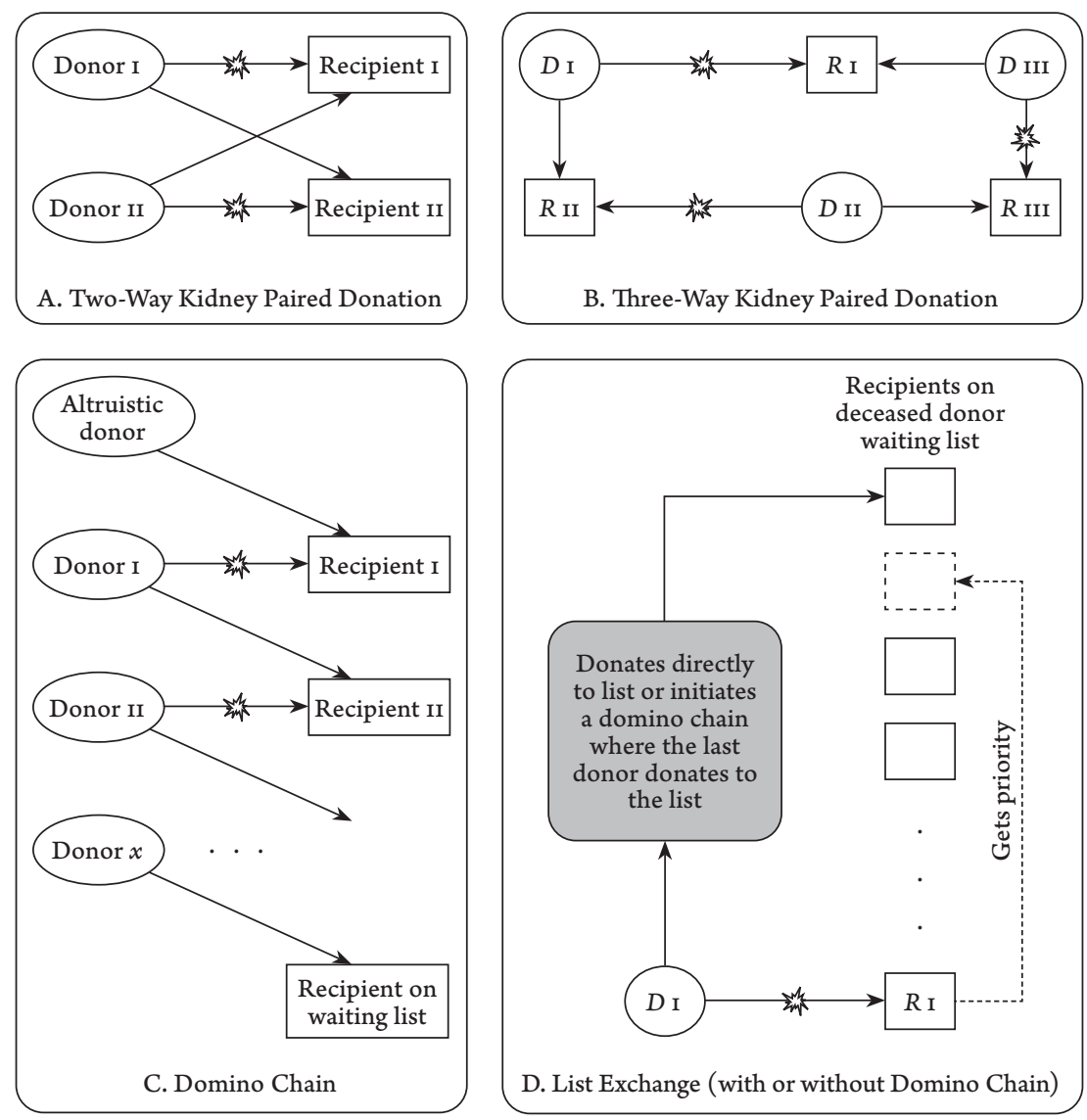

FIGURE 1 Simultaneous ke procedures. A solid arrow from $a$ to $b$ denotes an intended kidney donation from $a$ to $b$. An exploding arrow denotes incompatibility of the intended donor.

rected" donor is defined in this context as someone who gives a kidney to a stranger without receiving compensation. ${ }^{12}$ In the absence of KE, altruistic donor kidneys are allocated to compatible patients ranked high on the waiting list. When combined with $\mathrm{KE}$, an altruistic donor does not donate directly to the list. Instead, they donate to the recipient of an incompatible pair, whose incompat-

12 Altruistic donors do not typically specify a person they wish to receive their kidney, which is why "non-directed" and "altruistic" refer to the same class of donors. However, in some countries (e.g., the UK), directed altruistic donations are legal, that is, donors may donate to specific but unrelated persons, for example, a patient whose predicament was reported on TV. Directed altruistic donations may give rise to "repugnance" (Roth, "Repugnance as a Constraint on Markets"), for example if they produce markets for attention among patients with end-stage renal disease. However, they appear to be a marginal phenomenon and will not be considered here. 
ible donor simultaneously donates to the recipient of yet another incompatible pair, and so on, up to the last donor, who donates to a patient on the waiting list. Since the altruistic donation kicks off various transplants, the resulting chains are called "domino chains." ${ }^{13}$ A domino chain is shown in part c of figure 1.

Similarly, paired donations could be combined with list exchanges, as in part D of figure 1. In conventional list exchanges, the donor of an incompatible pair donates to a patient on the waiting list and in return her recipient gets priority on the list. Instead of donating directly to the list, the donor could also donate to the recipient of another incompatible pair, thus kicking off a sequence of simultaneous exchanges, in which the last donor donates to the list and the recipient of the first donor gets priority on the list. ${ }^{14}$

Each of the procedures A-D triggers at least two transplantations, which are carried out simultaneously. This is because the promise to give a kidney is not legally enforceable, which poses the problem that in nonsimultaneous chains, possible donors might renege on their promise to donate once their recipient receives a kidney. The size of simultaneous chains is circumscribed, in particular by hospitals' logistics (each transplantation requires two operating rooms, and hospitals cannot accommodate many transplantations simultaneously), or by geography (kidneys must be transplanted quickly and should therefore not travel far).

However, there have been successful, "nonsimultaneous, extended, altruistic donor" (NEAD) chains. ${ }^{15}$ These consist of segments of domino chains, as shown in figure 2. The last donor of a segment becomes a "bridge donor": instead of simultaneously donating to the waiting list, they initiate a new segment at a later date. There are two types of NEAD chains: Closed NEAD chains specify a last donor, who donates to the waiting list simultaneously with the other donations of the last segment. Open-ended NEAD chains, in contrast, consist of indefinitely many segments. They end only when a bridge donor is ineligible to donate (e.g., because of a difficult-to-match blood type), or if they renege on their promise to donate. Being nonsimultaneous, NEAD chains alleviate the logistical obstacles that confine simultaneous chains. They promise a further increase in chain lengths, some of which have reached over thirty recipient-donor pairs in recent

13 Montgomery et al., "Domino-Paired Kidney Donation"; Roth et al., "Utilizing List Exchange and Nondirected Donation through 'Chain' Paired Kidney Donations.” Roth et al., "Utilizing List Exchange and Nondirected Donation through 'Chain' Paired Kidney Donations.”

Rees et al., "A Nonsimultaneous, Extended, Altruistic-Donor Chain." 


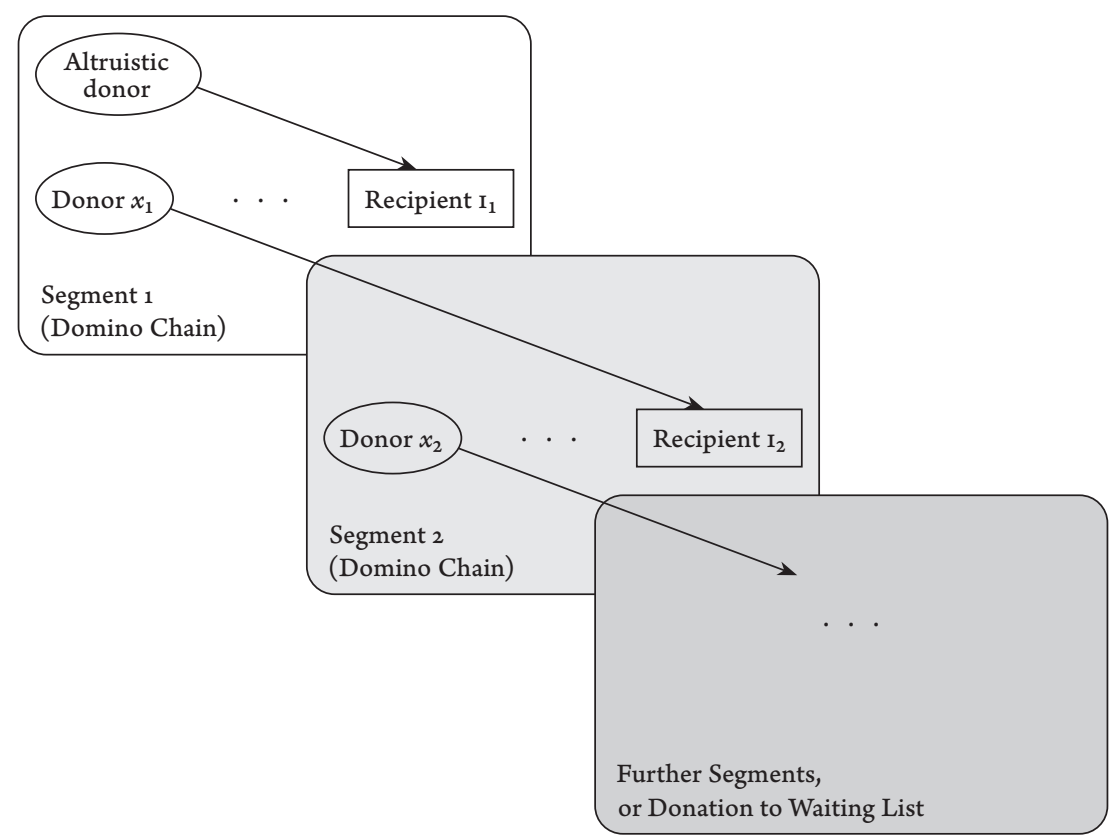

FIGURE 2 Nonsimultaneous, extended, altruistic donor (NEAD) chain. An altruistic donor initiates a domino chain (segment 1 ). The last donor from segment 1 (denoted $x_{1}$ ) becomes a bridge donor and initiates another domino chain (segment 2) at a later date. The last donor of segment 2 either donates to the waiting list, in which case the NEAD chain ends, or becomes a bridge donor and initiates segment 3 , and so on.

years. ${ }^{16}$ However, they raise ethical and motivational issues for the bridge donors, which we will encounter below.

KE programs are being increasingly implemented in many countries. ${ }^{17}$ Further developments that promise additional increases in the numbers and the quality of transplantations include global kEs, some of which have already taken place. ${ }^{18}$ The integration of compatible pairs into KE is also possible if those pairs would profit from the exchange, or if they wish to engage in altruistic behavior. ${ }^{19}$

However, while $\mathrm{KE}$ is expanding, it is at the same time meeting ethical concerns. These are embodied in the transplant laws in various countries that vir-

16 Ashlagi et al., "Nonsimultaneous Chains and Dominos in Kidney-Paired Donation-Revisited."

17 E.g., Roth, “Transplantation” and "Marketplaces, Markets, and Market Design.” For Europe, cf. Biró et al., "Building Kidney Exchange Programmes in Europe."

18 Rees et al., "Kidney Exchange to Overcome Financial Barriers to Kidney Transplantation."

19 Roth et al., "Kidney Paired Donation with Compatible Pairs"; Wallis et al., "Kidney Paired Donation.” 
tually ban KE programs. For instance, German legislation permits donations only from persons of first and second degree of relationship, or who otherwise "manifestly stand in a special, personally close relationship" to the recipient. ${ }^{20}$ This restriction makes most KEs and all altruistic donations, which are by definition provided by strangers, illegal. There have been piecemeal two-way kidney paired donations where the two incompatible pairs established personally close relationships with each other, thus allowing for legal paired donation. However, since the requirements on exhibiting such a relationship are high, and in the absence of an appropriate clearinghouse, success via this path is unlikely. This is even more so for three-way exchanges, the integration of which would achieve a more efficient use of the donor pool. Domino and list exchanges are rendered altogether impossible.

Germany is not an isolated case. In Europe, similarly restrictive laws are in effect in Bulgaria, Estonia, Finland, and Hungary, among others. ${ }^{21}$ Less but still relatively restrictive laws prevail in Belgium, France, Greece, Poland, and Switzerland, which are more permissive concerning kidney paired donation, but prohibit altruistic donations, thus ruling out domino chains. ${ }^{22}$ Thus, there seem to be concerns in particular about altruistic donations, leading many countries to impose restrictive transplant laws that rule out various forms of KE.

We shall uncover the possible objections to different forms of live kidney donations and their implications for KE in section 4. Before proceeding to that, we will examine KE in view of the effectiveness principle. For the time being, we shall assume that all types of live kidney donations, including altruistic donations to strangers, are feasible.

\section{KIDNEY EXCHANGE AND THE EFFECTIVENESS PRINCIPLE}

It will not come as a surprise what the effectiveness principle and its extensions imply for the allocation of live kidney donations. Yet we need to take care not to jumble different types of kidney donors. This section will consider the most important types of donors successively, and it will end by examining the implications for KE programs.

First, consider altruistic donors. When an altruistic donor donates to the wait-

The author's translation from paragraph 8 of the German Transplant Law, version from September 4, 2007 (BGBl. I S. 2206), changed by article 2 from November 21, 2016 (BGBl. I S. 2623).

Wissenschaftlicher Dienst, "Die Cross-over-Lebendspende," 17; and Lopp, Regulations Regarding Living Organ Donation in Europe.

22 Biró et al., “Building Kidney Exchange Programmes in Europe," esp. 12 and table 1. 
ing list, they may help one patient on that list. If they donate into KE instead, they trigger a KE chain, thereby helping at least two, but possibly many more patients if the transplantations are successful. From this and the effectiveness principle it follows that, when an altruistic donor is offered the choice between donating into a waiting list or into $\mathrm{KE}$, morality requires the latter. Moreover, $\mathrm{KE}$ programs use optimization algorithms that maximize the number of possible matches within the pool of possible donors and recipients, subject to quality constraints (see below). The use of these algorithms guarantees that no possible allocation of kidneys in this pool could be more effective, given those quality constraints. Therefore, an altruistic donor donating into $\mathrm{KE}$ is thereby donating as effectively as possible.

So far, we have talked as if comparing successful transplants in the presence versus the absence of KE. But there is no guarantee for success: in a small number of cases, graft loss or other complications occur for the recipient. When an altruistic donor is offered the choice between donating into a waiting list or into $\mathrm{KE}$, they do not know who would receive their kidney in each case and the respective chances of success. Before KE programs were in effect, altruistic donations were typically allocated to patients ranked high on the waiting list in such a way that takes the match quality into account—including factors such as blood type compatibility, sensitization, and age. This increases the chances of success. Similarly, the optimization algorithms used in Ke may include all the factors that figure into the list allocations, thus achieving similarly high levels of success. ${ }^{23}$ So altruistic donors have no reason to believe that the chances of success differ systematically for donating into KE versus donating to the waiting list. In this situation, the first extension of the effectiveness principle applies. According to this extension, the effectiveness principle is in effect when the benefits of the donation accrue with probability $<1$ and there is no reason to believe that this probability differs systematically for the beneficiaries under the two possible allocations. Thus, this principle requires donating into KE in the probabilistic case as well.

In contrast to altruistic donors, directed donors have agent-relative reasons that may block the obligation to donate into $\mathrm{KE}$, as the other-things-equal clause of the effectiveness principle applies when a donor wishes to help a relative or friend. If they are compatible, it is usually uncontroversial that that person will receive the organ. If they are not compatible, it might nevertheless be possible for the recipient to receive a kidney through paired donation. So they may engage in KE and thereby achieve an effective allocation, but effectiveness results as a by-product: it is not the effectiveness that requires the donor to engage in the

23 Rees et al., "A Nonsimultaneous, Extended, Altruistic-Donor Chain," 1100. 
paired donation, but the agent-relative reason that a donation to a stranger will provide a transplant for their loved one.

Next, consider donors eligible for bridge donation in NEAD chains. Remember that a bridge donor donates to a stranger after their recipient receives the transplant and the donation triggers a domino chain that constitutes a segment of a NEAD chain. A donor who is eligible for bridge donation may be offered the choice between donating to a waiting list simultaneously to their recipient receiving the transplant, or triggering a domino chain at a later date. Their motivation for donating is to help the intended recipient and thus differs from that of an altruistic donor. If they decide to become a bridge donor, they donate to a stranger because they honor their promise to do so after the recipient received the transplant. They typically would not have donated to a stranger otherwise, and would have donated to the recipient if compatible. Bridge donors' motivation gives rise to concerns that they might renege on their promise to donate once their recipients receive the transplant, as discussed in section 4. Here, we note that the second extension of the effectiveness principle applies to persons who are eligible for bridge donation. It states that the effectiveness principle is indifferent to the motivation for donating. Thus, for a donor who is offered the choice to donate into a list (simultaneously with their recipient receiving a transplant) or to trigger a chain (at a later date), morality requires the latter. ${ }^{24}$

It is less clear whether the same holds for donors of compatible pairs who are offered the choice to take part in KE. They may accept this offer for a range of reasons, for example that their recipient would profit from a kidney paired donation because of a better match. Or they refuse the offer, for example when the compatible recipient prefers the organ of a related party to a stranger's. In such a case, there might be legitimate agent-relative reasons for not donating into $\mathrm{KE}$ and the effectiveness principle does not apply. In other cases, in which there are no relevant agent-relative reasons to prefer donating directly to their loved ones, the effectiveness principle applies, requiring them to take part in KE.

Finally, consider the third extension of the effectiveness principle: it is not permitted to prevent a donor from exercising their conditional obligation to do-

24 If a donor has the choice to donate at the point in time in which her recipient also receives a kidney, or to trigger a chain at a later date, the time lag might constitute a morally relevant factor for her decision. This is because, for reasons of time discounting, a kidney transplant for a single person in need now may have more value than kidney transplants for many persons in the distant future. However, discounting is unlikely to be significant in this context because the time frames in question are relatively short. For instance, Fumo et al. argue that bridge donors' waiting times should be subject to a maximum limit of seven to twelve months ("How Long Is Too Long?"). Arguably, only under unreasonably high discount rates would this justify sacrificing the value of a future chain for a single transplant now. 
nate effectively. Concerning the relevant donor groups above-altruistic donors, donors eligible for bridge donation, and some compatible pairs- $\mathrm{KE}$ is instrumental in meeting the conditional obligation to donate effectively. Thus, it is morally wrong to prevent these donors from donating into KE. It is then only a small step to conclude that it is wrong not to allow KE. This is because it is plausible to assume that if it is morally wrong to prevent someone from acting in an institution and there are no good independent reasons for prohibiting that institution, then it is morally wrong not to allow the institution. We shall see in section 4 that the alleged reasons against KE programs are in fact not good reasons. ${ }^{25}$ It follows that it is morally wrong not to allow KE programs.

To sum up, weak principles from the ethics of giving have two important implications for live kidney donation: (i) there is a conditional obligation for altruistic donors and donors eligible for bridge donation, and for some compatible pairs, to donate into KE instead of into a waiting list, if they can choose to do so; and (ii) since KE is instrumental in meeting the conditional obligation to donate effectively, it is wrong to prohibit KE if there are no independent reasons for doing so (a condition that will be discussed below).

The effectiveness principle may have other implications that will not be considered in depth here. For example, it might be applied to make a case for global $\mathrm{KE}$, which has the potential to substantially increase pool sizes and thus numbers and quality of transplants. However, global KE may give rise to separate ethical issues, for example, possible organ trafficking and unreliable medical care in developing countries, and it has generated opposition on these grounds. ${ }^{26}$ These are difficult issues, worthy of a separate paper, and will therefore not be considered here.

\section{THE SCOPE OF KE AND THE DESIGN OF TRANSPLANT LAWS}

Where do the ethical concerns stem from, which are embodied in many transplant laws that virtually ban KE programs? There are various potential issues that we have ignored in the argument from the effectiveness principle. We shall first discuss influential arguments against donations from strangers, which rule out

25 Note that allowing KE programs does not necessarily mean allowing every possible instance of KE; as we shall see, there might be good reasons for restricting the scope of KE programs. But even if there is reason to think we should not allow some instances of $\mathrm{KE}$, say, those resulting from NEAD chains, this could easily be institutionalized in a KE program that does not offer NEAD chains (in fact, most existing KE programs are of this kind), so it is not a reason to prohibit KE programs. Thanks to an anonymous reviewer of this journal for pressing me on this point.

Delmonico and Ascher, "Opposition to Irresponsible Global Kidney Exchange." 
most KEs. The Research Section of the German Federal Parliament provided a rich source of these arguments in a technical report. ${ }^{27}$ We then discuss narrower arguments for restricting the scope of KE programs, which stem from concerns about specific types of KE, especially NEAD chains. Finally, the implications of this discussion for the design of transplant laws will be considered.

\subsection{Arguments against Donations from Strangers}

Protecting donors from possible harms. There is no evidence that live kidney donations significantly decrease donors' life expectancy or quality of life. ${ }^{28}$ However, like any invasive surgery, they entail small risks of medical complications, including a very small, nonzero probability of death. These are possible harms to healthy persons who receive no medical benefits from the surgery. Therefore, removing a kidney from such a person might be argued to violate the physician's duty to "do no harm." Accordingly, one of the reasons why the German transplant law prohibits donations from strangers is to protect live donors from such harms that their decision to donate might entail.

But risk does not imply harm. Prohibiting live donations on the basis of donor protection would require a duty to incur no risks of harm, or, more reasonably, no risks above certain thresholds, which must arguably be set relative to the benefits to the recipient. This is not the place to argue for a specific threshold that is acceptable for live kidney donations, but it may nevertheless be helpful to compare their risks to some other risks that many people face in their daily lives. It is estimated that 3.1 per 10,000 kidney donors die during or within the first ninety days of their donation. ${ }^{29}$ This mortality rate is comparable to working in refuse and recyclable material collection for a year, according to statistics on occupational hazards. ${ }^{30}$ It is five times smaller than a year working in logging, which is listed as the most dangerous profession in these statistics. It has been argued, not least by medical practitioners, that these risks are reasonably low. ${ }^{31}$ Moreover, they are arguably far outweighed by the benefits to the recipient. Fur-

27 Wissenschaftlicher Dienst, "Die Cross-over-Lebendspende."

28 For a detailed discussion, cf. Tenenbaum, "Bartering for a Compatible Kidney Using Your Incompatible, Live Kidney Donor," 136-39.

Segev et al., "Perioperative Mortality and Long-Term Survival Following Live Kidney Donation."

30 See Bureau of Labor Statistics, "National Census of Fatal Occupational Injuries in 2016."

31 For example, Richard B. Freeman writes, "We expose patients to all kinds of risks every day for presumed benefits. Moreover, people willingly assume risks in their everyday lives, often much greater than those imposed by donor surgery, that have little or no direct benefit to their health. The risk that the harms from kidney donation will occur is very small compared with many risks we all face in everyday life" ("The Limits of Altruism," 273). 
thermore, presupposing that donors are mentally healthy and not subject to coercion or exploitation (concerns that will be discussed below), it seems they have a right that their autonomous choice be respected. ${ }^{32}$

More central for our purposes is the fact that Germany and other countries allow directed donations while prohibiting donations from strangers. Their implicit assumption seems to be that the risk of harm to directed donors is justifiable but the risk of harm to non-directed donors is not. But these risks do not differ systematically. So the claim that non-directed donors are more in need of protection from their decision to donate must be based on other considerations than risk: it must be based on considerations justifying that the same level of risk is acceptable for directed but not for non-directed donors.

A possible consideration that would justify this is that non-directed donors are mentally ill, while directed donors are not. This is a suspicion that altruistic donors' apparently selfless decision to give an organ to strangers sometimes arouses. But it seems unreasonable to take donors' altruism as evidence for mental illness. Of course, it should be ruled out that a person is donating an organ as a result of impaired judgment due to mental illness. In practice, there is extensive screening of all kinds of living donors - not altruistic donors alone - in order to rule out mental health issues. ${ }^{33}$ Skeptics might challenge the reliability of such tests. But it would be unreasonable to suppose that a directed donor who passed the test is mentally healthy while casting doubt on the mental health of an altruistic donor who passed the test, which is what this line of argument for justifying the restriction of the donor pool would require. We shall next examine another possible justification of the restriction.

Coercion. Germany also justifies the restriction of the legal donor pool with the need to rule out the possibility of coerciveness of donations and to secure their voluntariness. If it could be argued that anonymous donations entail an element of coercion that directed donations to family members and especially personally close persons do not, this would indeed constitute an argument for the restriction. To examine whether this is the case, we shall consider what a coerced donation could amount to.

In most countries, human kidneys are not for "valuable consideration." This is a legal term, meaning that it is prohibited both to donate and to receive kidneys in exchange for money or other valuable goods or services. A promise is only le-

32 Cronin, "Allowing Autonomous Agents Freedom."

33 For the practices in various European countries, cf. Working Group on Living Donation, “Toolbox Living Kidney Donation." For screenings of non-directed donors in the us, see Tenenbaum, "Bartering for a Compatible Kidney Using Your Incompatible, Live Kidney Donor," esp. 148-49 and the references in n. 177. 
gally enforceable if it is for valuable consideration. Thus, a promise to donate a kidney is not legally enforceable. This rules out the strongest form of coercion, which would subject the provision of a kidney to a legally binding contract. It also rules out possible exploitation of the poor, as it is impossible to sell kidneys.

However, as legal scholars point out,

consideration is a slippery doctrine... [D]onors are allowed to direct that their kidneys be given to certain people: family members, friends, and others. This might seem like a transfer without valuable consideration, but that is not necessarily the case. The donor might transfer to such people rather than to a stranger because she expects to receive something in return-for example, household services or help in some other matter. Only a donation to an anonymous stranger could clearly be without consideration. Nonetheless, the common law of contract generally treats intrafamily transfers as occurring without consideration, and regulated entities and regulators have apparently taken this position for kidney donations to friends and family, as well. ${ }^{34}$

Thus, compensation and coercion are harder to rule out when someone donates to a relative or friend. The organization of KE programs in countries where they are legal reflects this concern that personal relations can be instrumental for exercising coercion. Not only do transplant centers seek to rule out coercion through extensive background checks of potential donors, interviews, and education; it is typically also made impossible for mutually unacquainted persons in KEs to contact each other prior to the donation. There are various practical measures to enforce this, such as using different hospital sites. Some countries, e.g., Australia, discourage donors and recipients to meet even after the donation in order to rule out the possibility of posterior compensations, or of raising accusations, for example after graft loss.

Alas, there is no guarantee that donations are always entirely free of some soft forms of coercion, in particular in emotionally close relationships. The argument that restricting the donor pool to especially close persons would help secure the voluntariness of a donation gets it the wrong way around. The altogether different conclusion here is that if you want to allow directed, e.g., intrafamily donations - as most countries, including Germany, do-then there is no reason based on coerciveness for prohibiting anonymous donations, including altruistic donations.

There is a more subtle issue concerning coercion in NEAD chains, which will be considered below.

34 Choi et al., "Altruism Exchanges and the Kidney Shortage," 290-91. 
Slippery slope: KE and the commercialization of human organs. Germany also adduces the prevention of organ trade as a reason for the limitation of the donor pool. However, this argument is not convincing. It is empirically unfounded, as most countries condemn the practice of buying and selling organs and there is not a single country that has commercialized organ donations after implementing $\mathrm{KE}$ programs. ${ }^{35}$ Concerning black markets, there is no reason to believe that they are more likely to develop in the presence of KE. (It might be argued that the opposite is the case because ke helps to decrease the demand for kidneys.) Finally, the argument also commits the fallacy encountered before: Why should it help for preventing valuable consideration in kidney donations to restrict the donor pool to especially close persons, where the risk of valuable consideration is higher?

\subsection{Concerns about Specific Types of KE}

Trade-offs between efficiency and fairness. As we have seen, without KE, altruistic donations are allocated to compatible patients ranked high on a deceased donor waiting list. Now, suppose that an altruistic donor decides to donate into $\mathrm{KE}$ instead of to the list. The resulting concern is most visible in open-ended NEAD chains. Remember that these chains end only when a bridge donor becomes ineligible or reneges on their promise to donate. As a result, there is no kidney that will be allocated to the waiting list. Closed NEAD chains, in which a last donor is specified who will donate to the waiting list, are not necessarily subject to this diversion of kidneys from the list. But even in closed NEAD chains, the last donor might not end up donating to the list, for example, if the bridge donor of an earlier segment reneged on their promise to donate, which terminated the chain prematurely.

The allocations of kidneys resulting from NEAD chains raise concerns because deceased donor waiting lists incorporate medical but also fairness principles, such as time already spent waiting, or priority of children over adults. Thus, NEAD chains, by diverting kidneys from the list, might go against a fair allocation of kidneys. Furthermore, when kidneys are not allocated to the list, those particularly vulnerable patients on the list who do not have living donors might be disadvantaged because they are not eligible to participate in KE.

On the other hand, NEAD chains achieve large numbers of transplants. Thus, these chains can be seen as promoting efficiency at the expense of fairness. Proponents of NEAD chains typically counter this concern by arguing that the efficiency that NEADS achieve helps patients on the waiting list too, namely by removing multiple patients from the list. ${ }^{36}$ Yet, diverting altruistic donations from 
the list may disadvantage at least some patients on the list. In particular, a patient does not profit if lower-ranked patients are removed from the list, so patients that are already highly ranked can be expected to be disproportionately disadvantaged.

Unlike NEAD chains, other types of KES do not in principle divert live donor kidneys from waiting lists. However, combining KE with waiting lists may disadvantage blood-type $\mathrm{O}$ patients on the list. The reason is, very roughly, that blood-type $\mathrm{O}$ patients can receive kidneys only from $\mathrm{O}$ donors, whereas $\mathrm{O}$ donors can donate to all blood types. Now, consider as an example a domino chain that an altruistic donor triggers and that ends with an incompatible donor donating to the list. The distribution of blood types among altruistic donors resembles that of the general population. Therefore, there is a high probability that this donor is $\mathrm{O}$ and will donate to a hard-to-match $\mathrm{O}$ recipient. But it is unlikely that the incompatible donor who donates to the list is $\mathrm{O}$, otherwise they would likely be compatible with the recipient. Thus, KE may systematically divert highly demanded $\mathrm{O}$ kidneys from the list. ${ }^{37}$

Woodle et al. suggest that the crucial ethical question concerning the tradeoff between efficiency and fairness is this: How many additional transplants must the inclusion of altruistic donors into KE chains generate in order to justify the diversion of altruistic donors (in NEAD chains), or of blood-type $\mathrm{O}$ altruistic donors (in general) from the waiting list $?^{38}$ Transplant laws could do justice to a specific answer to this question by stipulating that the inclusion of altruistic donors into KE requires a minimum number of transplants. Moreover, concerning the loss of $\mathrm{O}$ donors, they suggest "a requirement that, for every [altruistic donor] kidney donated to initiate a ke chain, a kidney of the same blood type must be donated to the [waiting list] at the end of the KE chain."39

Risks for bridge donors. NEAD chains entail the risk that bridge donors renege on their promise to donate. However, the rates of reneging bridge donors appear to be small, and it has been argued that the utility benefits from NEAD chains outweigh these risks. ${ }^{40}$

There is yet another worry concerning bridge donors. NEAD chains are

A similar concern arises in list exchanges (conventional or combined with domino chains). For a discussion, see den Hartogh, "Trading with the Waiting-List." Woodle et al., "A Prospective, Randomized, Multicenter Study Evaluating Early Corticosteroid Withdrawal with Thymoglobulin in Living-Donor Kidney Transplantation." Woodle et al., "A Prospective, Randomized, Multicenter Study Evaluating Early Corticosteroid Withdrawal with Thymoglobulin in Living-Donor Kidney Transplantation," 1464.

40 Wallis et al., "Kidney Paired Donation"; Tenenbaum, "Bartering for a Compatible Kidney Using Your Incompatible, Live Kidney Donor.” 
formed on the understanding that the bridge donors will donate to initiate a segment of transplants after their partners receive transplants (assuming that they continue to be medically and psychologically eligible). Because they gave this promise beforehand, they may feel obliged to donate after their recipients receive transplants. Bridge donors know that if they bail out they thereby break the promise they gave, on the basis of which their partners received their transplant and on which various persons in need of kidneys rely. This might impose pressure on them, which may be felt as a form of coercion. It has been argued that it is morally problematic to put people in this position, and NEAD chains have been criticized on these grounds. ${ }^{41}$

There are various measures to diminish the risk that bridge donors feel coerced through their promise to donate. Transplant centers select and educate possible bridge donors carefully. It may also be possible to relieve them from some of the felt pressure to be triggering a great number of transplants simply by not telling them how long the chain will be prior to their donation. Moreover, since evidence suggests that the level of felt coercion increases with time, time limits can be set within which their donation should happen, otherwise their promise is void. Alternatively, a more conservative solution would be to restrict KE programs to the simultaneous cases.

\subsection{Implications for the Design of Transplant Laws}

The principled arguments against donations from strangers, which preclude most KEs, have been found wanting. However, it might be ethically required to restrict the scope of KE procedures. In general, the efficiency gains from allowing broader KEs must be weighed against increasing concerns with respect to the diversion of altruistic donors, especially type-O donors, from waiting lists and, in the case of NEAD chains, the potential felt coercion of bridge donors. My aim was not to argue for a specific weighting. Instead, the argument is the following. Suppose we take a conservative view and put heavy weight on avoiding the diversion of altruistic donors, especially $\mathrm{O}$ donors and on minimizing the possibility that bridge donors feel coerced into donating. A transplant law embodying this view might restrict or even prohibit NEAD chains. It may also require that KE chains divert altruistic donations from the list only when they achieve a large number of transplants, and it may prescribe the prevention of $\mathrm{O}$ donor loss. The result would be a transplant law that places heavy weight on donor protection and allocative fairness with respect to patients without living donors. The point is that this legislation would not resemble the transplant laws we encountered

41 For discussion, see Tenenbaum, "Bartering for a Compatible Kidney Using Your Incompatible, Live Kidney Donor." 
earlier, such as the German transplant law, which require a personally close relationship between donor and recipient. Even a conservative view on live kidney donation, if sound, does not in principle reject KE programs.

\section{THE ATTRACTION OF EFFECTIVENESS}

KE may generate motivational benefits for donors. Consider the following report from Dylan Matthews, who altruistically donated his kidney in 2016:

The very same day that I donated, [the recipient's] relative had their kidney taken out as well and flown to the West Coast. This second recipient also had a friend or relative agreeing to an exchange; so did the third recipient, who got the second recipient's friend's kidney. Our chain will let people enjoy 36 to 40 years of life they would've otherwise been denied.

Our four kidneys were pretty good, but some chains can go even longer. A chain started by a 44-year-old man in California named Rick Ruzzamenti wound up getting 30 people kidneys. Ruzzamenti's chain let people live 270 to 300 years longer. You can literally measure the years of life his kidney donation chain gave in centuries. ${ }^{42}$

Matthews does not go so far as to suggest that he, or Ruzzamenti, decided to donate because of the potentially large numbers of life years that their donations would enable. But the passage provides clear evidence for the awe that donors experience when considering the large impact of their donations in terms of life years gained. This naturally suggests the hypothesis that, other things being equal, a donor's motivation is higher if the possible number of transplants triggered, or of life years saved, is higher.

This hypothesis, if true, has implications for KE. As we have seen, KE programs use optimization algorithms that increase the number and quality of transplants. Thereby, they increase the number of lives saved, or of life years gained. ${ }^{43}$ It follows that, if the motivation for donating is partly determined by and increases with the impact of the donation, $\mathrm{KE}$ increases the motivation for donating. The argument would apply to all donors who are partly motivated by altruism. This includes altruistic donors, but also other types—-such as directed donors, bridge donors, and compatible pairs - as they may often be partly motivated by altruism as well.

Matthews, "Why I Gave My Kidney to a Stranger."

Different algorithms may have unequal implications concerning numbers of lives saved and of life years gained. We can neglect this point here because an altruistic donation will typically increase both variables if $\mathrm{KE}$ is in effect as compared to the default of no $\mathrm{KE}$. 
In light of the striking shortage of kidneys for transplantation, if KE programs promote altruistic behavior, this constitutes a significant advantage. Thus, the hypothesis that the motivation for kidney donations is partly determined by the amount of good they can be expected to achieve, if true, constitutes a second, motivational argument for the implementation of KE programs.

This is not the place to investigate whether the hypothesis is true. It is an empirical hypothesis that could be confirmed by comparing trajectories of altruistic donations in countries where KE programs exist to countries where they do not. We note here merely that the available evidence is consistent with the hypothesis. In many countries in which centralized ke programs exist, e.g., in the US and the UK, the numbers of altruistic donations have been increasing in recent years. ${ }^{44}$ More generally, there is evidence that donating effectively can boost donors' motivation. ${ }^{45}$ We conclude that it is a reasonable hope that $\mathrm{KE}$ promotes the emergence of altruism.

In contrast, transplant laws that restrict the donor pool to relatives and persons manifestly close to recipients entail problematic incentives. Concerning altruistic donations, they convey the image that there is something unethical about the gift to a stranger. Moreover, concerning kidney paired donations, members of mutually compatible pairs will have incentives to pretend that there are personally close relationships even when there are not. But such incentives to "game the system" cannot be in the interest of legislative authorities, and they are detrimental for building trust in the system. These motivational considerations speak against prohibiting live organ donations to strangers, and in favor of making effective use of them through KE.

\section{CONCLUSION}

Weak principles from the ethics of giving make a strong case for KE programs. These programs are instrumental in allowing kidney donors to meet the conditional moral obligations implied by those principles. Therefore we ought not to preclude people from fulfilling these obligations by banning KE. There might be ethical reasons for restricting specific procedures of $\mathrm{KE}$, but these reasons do not

44 For data on altruistic donations in the UK, see Robb et al., "Annual Report on Living Donor Kidney Transplantation." For the us, see, e.g., Tenenbaum, "Bartering for a Compatible Kidney Using Your Incompatible, Live Kidney Donor."

45 Parbhoo et al., "Best of Intentions," 21. In a survey, 85 percent of donors revealed that they paid very close attention to effectiveness when giving to charities, and even though they care about effectiveness, few donors spend time investigating the effectiveness of the charities they give to. So admittedly, the evidence is somewhat mixed. 
in principle reject KE programs. Finally, KE may achieve motivational benefits that constitute a further argument in its favor.

The arguments given here are not wedded to a specific moral theory. They will appeal to effective altruists, but because of their weak, conditional premises, many people who are not committed effective altruists will welcome them as well. They are also consistent with conservative views on donor protection and allocative justice concerning patients on waiting lists. I hope that these arguments will lead to a clarification of the debates about the ethics underlying KE programs, particularly in countries that have hitherto banned these programs.

This paper calls for various follow-up projects. First, we explicitly excluded global KE, which has the potential to substantially increase the numbers and quality of transplants. Ethicists are called for to weigh these benefits against the concerns that have been raised about global $\mathrm{KE}$, for example, whether the risk of organ trafficking can be ruled out sufficiently in some developing countries. Second, the hypothesis about donors' motivation on which our argument from attractiveness draws should be investigated empirically. Third, in many countries that currently prohibit live donations to strangers, changes to legislation, for which we argued here, may not be feasible in the short or medium term. In the meantime, some "slim" forms of KE programs might be implemented in those countries. For instance, restrictions of the donor pool to persons that are emotionally close to the recipient provide the possibility to match donor-recipient pairs that could in the next step meet in person and establish the required relationship. This could enable some types of KE, in particular kidney paired donations, which are currently conducted only sparsely in those countries. Making the most of existing transplant laws would improve the predicament of many people suffering from kidney disease, but it does not excuse decision makers' inaction. ${ }^{46}$

Leibniz University Hannover London School of Economics and Political Science philippe.van.basshuysen@philos.uni-hannover.de

46 I thank Luc Bovens, Paul Daniell, Jurgis Karpus, David Kinney, Theron Pummer, Bryan Roberts, Thomas Rowe, Bastian Steuwer, Alex Voorhoeve, and Jannik Zeiser, as well as anonymous referees of this journal, for helpful comments and/or discussions at various stages of this research. I also thank the audience at the Cognition, Value and Behaviour Lab Meeting at LMU Munich for valuable discussions. Part of this research was supported by Volkswagenstiftung within the project "Bias and Discrimination in Big Data and Algorithmic Processing: Philosophical Assessments, Legal Dimensions, and Technical Solutions.” 


\section{REFERENCES}

Ashlagi, Itai, Duncan S. Gilchrist, Alvin E. Roth, and Michael A. Rees. "Nonsimultaneous Chains and Dominos in Kidney-Paired Donation-Revisited." American Journal of Transplantation 11, no. 5 (May 2011): 984-94

Biró, Péter, Bernadette Haase-Kromwijk, Tommy Andersson, et al. "Building Kidney Exchange Programmes in Europe: An Overview of Exchange Practice and Activities." Transplantation 103, no. 7 (July 2019): 1514-22.

Bureau of Labor Statistics. "National Census of Fatal Occupational Injuries in 2016." News release, December 19, 2017. https://www.bls.gov/news.release/ archives/cfoi_12192017.pdf.

Choi, Stephen J., Mitu Gulati, and Eric A. Posner. "Altruism Exchanges and the Kidney Shortage." Law and Contemporary Problems 77, no. 3 (2014): 289-96.

Cronin, Antonia J. "Allowing Autonomous Agents Freedom.” Journal of Medical Ethics 34 (2008): 129-32.

Delmonico, Francis L., and Nancy L. Ascher. "Opposition to Irresponsible Global Kidney Exchange.” American Journal of Transplantation 17, no. 10 (October 2017): 2745-46.

Den Hartogh, Govert. "Trading with the Waiting-List: The Justice of Living Donor List Exchange.” Bioethics 24, no. 4 (May 2010): 190-98.

Freeman, Richard B. "The Limits of Altruism: Selecting Living Donors." American Medical Association Journal of Ethics 14 (2012): 272-77.

Fumo, David, Timothy Suttle, Ryan Flynn, Laurie Reece, Stanislaw Stepkowski, Michael Rees, and Jonathan Kopke. "How Long Is Too Long? The Impact of Bridge Donor Waiting Time on Paired Donation Transplants.” Journal of Urology 193, no. 4s (April 2015): e1015.

Horton, Joe. “The All or Nothing Problem.” Journal of Philosophy 114, no. 2 (February 2017): 94-104.

Lopp, Leonie. Regulations Regarding Living Organ Donation in Europe: Possibilities of Harmonisation. Berlin: Springer, 2013.

MacAskill, William. Doing Good Better: How Effective Altruism Can Help You Make a Difference. London: Random House, 2016.

Matthews, Dylan. "Why I Gave My Kidney to a Stranger-and Why You Should Consider Doing It Too.” Vox, April 11, 2017. https://www.vox.com/science -and-health/2017/4/11/12716978/kidney-donation-dylan-matthews.

McMahan, Jeff. "Doing Good and Doing the Best.” In The Ethics of Giving: Philosophers' Perspectives on Philanthropy, edited by Paul Woodruff, 78-102. New York: Oxford University Press, 2018.

Montgomery, Robert A., Sommer E. Gentry, William H. Marks, Daniel S. War- 
ren, Janet Hiller, Julie Houp, Andrea A. Zachary, J. Keith Melancon, Warren R. Maley, Hamid Rabb, Christopher Simpkins, and Dorry L. Segev. "Domino-Paired Kidney Donation: A Strategy to Make Best Use of Live Non-Directed Donation." Lancet 368, no. 9533 (July 2006): 419-21.

Parbhoo, Omar, Katy Davis, Robert Reynolds, Piyush Tantia, Pranav Trewn, and Sarah Welch. "Best of Intentions: Using Behavioral Design to Unlock Charitable Giving." Ideas42 Report, 2018. http://www.ideas42.org/wp-content/ uploads/2018/o8/ideas42-Best-of-Intentions_Charitable-Giving-1.pdf.

Parfit, Derek. "Future Generations: Further Problems." Philosophy and Public Affairs 11, no. 2 (Spring 1982): 113-72.

Pummer, Theron. "Whether and Where to Give." Philosophy and Public Affairs 44, no. 1 (Winter 2016): 77-95.

Rees, Michael A., Ty B. Dunn, Christian S. Kuhr, et al. "Kidney Exchange to Overcome Financial Barriers to Kidney Transplantation.” American Journal of Transplantation 17, no. 3 (March 2017): 782-90.

Rees, Michael A., Jonathan E. Kopke, Ronald P. Pelletier, et al. "A Nonsimultaneous, Extended, Altruistic-Donor Chain.” New England Journal of Medicine 360, no. 11 (March 12, 2009): 1096-101.

Robb, Mathew, Chloe Brown, and Lisa Mumford. "Annual Report on Living Donor Kidney Transplantation." NHs Blood and Transplant, October 2017. https://nhsbtdbe.blob.core.windows.net/umbraco-assets-corp/5706/ annual-report-on-living-donor-kidney-transplantation-2016_17.pdf.

Roth, Alvin E. "Marketplaces, Markets, and Market Design." American Economic Review 108, no. 7 (July 2018): 1609-58.

- . "Repugnance as a Constraint on Markets." Journal of Economic Perspectives 21, no. 3 (Summer 2007): 37-58.

- "Transplantation: One Economist's Perspective." Transplantation 99, no. 2 (February 2015): 261-64.

Roth, Alvin E., Tayfun Sönmez, and M. Utku Ünver. "Efficient Kidney Exchange: Coincidence of Wants in Markets with Compatibility-Based Preferences." American Economic Review 97, no. 3 (June 2007): 828-51.

Roth, Alvin E., Tayfun Sönmez, M. Utku Ünver, Frank L. Delmonico, and Susan

L. Saidman. "Utilizing List Exchange and Nondirected Donation through 'Chain' Paired Kidney Donations.” American Journal of Transplantation 6, no. 11 (November 2006): 2694-705.

- "Kidney Paired Donation with Compatible Pairs." American Journal of Transplantation 8, no. 2 (February 2008): 463.

Segev, Dorry L., Abimereki D. Muzaale, Brian S. Caffo, et al. "Perioperative Mor- 
tality and Long-Term Survival Following Live Kidney Donation." Journal of the American Medical Association 303, no. 10 (March 10, 2010): 959-66.

Singer, Peter. The Most Good You Can Do: How Effective Altruism Is Changing Ideas about Living Ethically. New Haven: Yale University Press, 2015.

Tenenbaum, Evelyn M. "Bartering for a Compatible Kidney Using Your Incompatible, Live Kidney Donor: Legal and Ethical Issues Related to Kidney Chains." American Journal of Law and Medicine 42, no. 1 (March 2016): 129-69.

Wallis, C. Bradley, Kannan P. Samy, Alvin E. Roth, and Michael A. Rees. "Kidney Paired Donation.” Nephrology Dialysis Transplantation 26, no. 7 (July 2011): 2091-99.

Wang, Haidong, Mohsen Naghavi, Christine Allen, et al. "Global, Regional, and National Life Expectancy, All-Cause Mortality, and Cause-Specific Mortality for 249 Causes of Death, 1980-2015: A Systematic Analysis for the Global Burden of Disease Study 2015." The Lancet 388, no. 10053 (October 2016): 1459-1544.

Wissenschaftlicher Dienst. "Die Cross-over-Lebendspende. Zum Stand in Deutschland und in ausgewählten europäischen Ländern.” Deutscher Bundestag, WD9-3000-022/17 (2017).

Working Group on Living Donation. "Toolbox Living Kidney Donation." March 2016. https://ec.europa.eu/health/sites/health/files/blood_tissues_ organs/docs/eutoolbox_living_kidney_donation_en.pdf.

Woodle, E. S., J.A. Daller, M. Aeder, R. Shapiro, T. Sandholm, V. Casingal, D. Goldfarb, R. M. Lewis, J. Goebel, and M. Siegler. "Ethical Considerations for Participation of Nondirected Living Donors in Kidney Exchange Programs." American Journal of Transplantation 10, no 6. (June 2010): 1460-67. 